\title{
Indoor air pollution and respiratory health in the elderly
}

\author{
M. Simoni*, M.S. Jaakkola\#, L. Carrozzi*, S. Baldacci*, F. Di Pede*, G. Viegi*
}

Indoor air pollution and respiratory health in the elderly. M. Simoni, M.S. Jaakkola, L. Carrozzi, S. Baldacci, F. Di Pede, G. Viegi. (C)ERS Journals Ltd 2003.

ABSTRACT: People spend about $\geqslant 80-90 \%$ of their daily time indoors, elderly people especially at home. Thus, it is important to investigate possible health effects of indoor air pollutants and to consider their contributions to the total human exposure.

This report summarises current knowledge on health effects of three common indoor air pollutants, respirable suspended particles, nitrogen dioxide and environmental tobacco smoke, with focus on the adults and the elderly. Preliminary findings on exposure distributions and health effects of these pollutants in older subjects of two panel studies carried out in Italian general populations will also be reported.

The two indoor pollution studies were performed in the Po Delta area in North Italy (428 subjects and 140 houses investigated) and in Pisa in Central Italy (761 subjects and 282 houses investigated). Individuals aged $\geqslant 65$ yrs spent a significantly larger number of hours at home than the other age groups both in winter and in summer. A trend of higher occurrence of acute respiratory symptoms in the presence of environmental tobacco smoke was shown in comparison to the unexposed elderly both in winter (31 versus 29\%) and summer (33 versus 16\%). The occurrence of acute respiratory symptoms was consistently higher in relation to the high respirable suspended particles-index exposure compared to low exposure (33 versus $27 \%$ in winter, 27 versus $21 \%$ in summer). Both the presence of environmental tobacco smoke at home and exposure to the high respirable suspended particles-index were associated with a decrease in the mean daily peak expiratory flow.

Eur Respir J 2003; 21: Suppl. 40, 15s-20s.
*Pulmonary Environmental Epidemiology Group, CNR Institute of Clinical Physiology, Pisa, Italy, ${ }^{\#}$ Finnish Institute of Occupational Health, Helsinki, Finland.

Correspondence: L. Carrozzi

CNR Institute of Clinical Physiology Via Trieste, 41

56126 Pisa

Italy

Fax: 39050503596

E-mail: carrozzl@ifc.cnr.it

Keywords: Elderly

indoor pollution

lung function

passive smoking

respiratory symptoms

Received and accepted: April 122002
Indoor air pollution is a major global public health problem requiring increasing efforts in research and policymaking [1]. The concentrations of several pollutants can be many times higher indoors than outdoors [2]. In addition, the presence of indoor pollutants, even at low concentrations, may have important biological impact because of long exposure periods. People spend $\geqslant 80-90 \%$ of their day indoors, and elderly people are likely to spend even more time at home $[2,3]$. Thus, indoor air pollutants may have special significance for this age group. Since the length of life expectancy is increasing in all developed countries, more efforts to study the effects of air pollution on the health of the elderly are needed, including studies on indoor air quality. Several studies have investigated the effects of indoor air pollution on health of infants and children [1, 4-10]. Some studies have shown evidence that indoor air pollution increases the risk of respiratory and atopic diseases even in adult populations [11-14], but information on health effects of such pollutants in the elderly is sparse.

The aim of this report is to summarise current knowledge on health effects of three common indoor air pollutants, namely respirable suspended particles (RSP), nitrogen dioxide $\left(\mathrm{NO}_{2}\right)$, and environmental tobacco smoke (ETS), focusing on the adults and the elderly. In addition, the home exposure distributions and health effects of these pollutants in older subjects in two Italian studies carried out in general adult populations will be presented [3, 15]. Finally, methodological issues and questions for future research will be discussed.
Health effects of respirable suspended particles, nitrogen dioxide and environmental tobacco smoke

Suspended particulate matter, which is produced by ETS, cooking, cleaning and renovation activities, unvented gas and kerosene heaters indoors, and by penetration from outdoors, is a common measurable indoor pollutant. Particles $>10 \mu \mathrm{m}$ are usually removed at the upper airways, whereas those $<10 \mu \mathrm{m}$ (i.e. RSP) may be deposited in the smaller airways and alveoli [16]. Recently, several studies have found strong associations between outdoor RSP levels and mortality and morbidity, especially in the elderly [17-18]. Some studies [19-20] have indicated a strong correlation between indoor and outdoor particulate matter (PM) concentrations, suggesting that outdoor concentrations may be considered as a proxy for indoor concentrations. On the other hand, other studies $[21,22]$ utilising personal monitoring have found only a small correlation between total personal PM exposure and outdoor concentrations, suggesting that indoor concentrations provide a major contribution to the total exposure and, thus, to the health effects.

Only a few studies have evaluated the effects of indoor RSP on respiratory health in adults (table 1) [14, 23, 24]. The study on indoor pollutants in the Po Delta area in North Italy [23] showed an association of relatively low levels of RSP with increased occurrence of acute respiratory symptoms. There was a significant positive association between RSP exposure and bronchitic and asthmatic symptoms in winter. In nonsmokers, a similar association was observed also in summer. 
Table 1.-Effects of indoor particulate matter level/coal smoke on respiratory health in selected earlier studies on adults

\begin{tabular}{|c|c|c|c|c|}
\hline $\begin{array}{l}\text { First author } \\
\text { [ref no.] }\end{array}$ & $\begin{array}{l}\text { Country } \\
\text { of study }\end{array}$ & Risk factor & Disease/condition & OR $(95 \% \mathrm{CI})$ \\
\hline \multirow[t]{5}{*}{ SIMONI [23] } & \multirow[t]{5}{*}{ Italy } & \multirow[t]{5}{*}{$\begin{array}{l}\text { PM2.5 (over median value versus } \\
\text { under median value) }\end{array}$} & $\begin{array}{l}\text { Chronic bronchitic and/or } \\
\text { asthmatic symptoms }\end{array}$ & $1.83(1.26-2.65)$ \\
\hline & & & Irritative symptoms & $1.68(1.22-2.31)$ \\
\hline & & & Lung function (PEF variation) & \\
\hline & & & Max amplitude: & $1.23(1.03-1.48)$ \\
\hline & & & Diurnal variation: & $1.26(1.05-1.51)$ \\
\hline \multirow{3}{*}{ Xu [14] } & \multirow{3}{*}{ China } & Use of coal stove & Respiratory symptoms & \\
\hline & & Either cooking or heating versus no & & $1.5(1.0-2.3)$ \\
\hline & & $\begin{array}{l}\text { Both cooking and heating versus } \\
\text { no/never smokers }\end{array}$ & & $2.1(1.5-3.1)$ \\
\hline \multirow[t]{12}{*}{ VENNERS $[24]^{\#}$} & \multirow[t]{12}{*}{ China } & \multirow[t]{12}{*}{ Median indoor PM10 $\mu \mathrm{g} \cdot \mathrm{m}^{-3}$} & Chronic phlegm (males) & \\
\hline & & & Rural Anging versus ref & $4.96(2.13-11.54)$ \\
\hline & & & Beijing versus ref & $8.78(4.49-17.18)$ \\
\hline & & & Wheeze (males) & \\
\hline & & & Rural Anging versus ref & $3.99(1.77-8.91)$ \\
\hline & & & Beijing versus ref & $5.26(2.71-10.21)$ \\
\hline & & & Chronic phlegm (females) & \\
\hline & & & Rural Anging versus ref & $1.52(0.52-4.45)$ \\
\hline & & & Beijing versus ref & $8.93(3.56-22.43)$ \\
\hline & & & Wheeze (females) & \\
\hline & & & Rural Anging versus ref & $2.91(1.18-7.18)$ \\
\hline & & & Beijing versus ref & $8.28(3.66-18.74)$ \\
\hline
\end{tabular}

PM10: particles with a 50\% cut-off aerodynamic diameter of $10 \mu \mathrm{m}$; PM2.5: particles with a 50\% cut-off aerodynamic diameter of $2.5 \mu \mathrm{m}$; PEF: peak expiratory flow; OR: odds ratio; CI: confidence interval. \# : Subjects (239 Anging City (reference (ref)); 248 rural Anging; 557 Beijing).

Moreover, the symptom duration was greater in the presence of high RSP exposure. With regard to peak expiratory flow (PEF) and its variability, an increase in RSP exposure was associated with an increase in both max amplitude and diurnal variation of PEF. A study on the effects of indoor particulate levels on respiratory health in Chinese neversmokers, aged 40-69 yrs, showed an association between increasing level of particulates and the risk of chronic respiratory symptoms [14]. Consistently with these results, a trend of increasing risks for respiratory symptoms with increasing indoor particles with a $50 \%$ cut-off aerodynamic diameter of $10 \mu \mathrm{m}$ (PM10) levels was shown in a more recent study on Chinese adults [24].

Another common and easily measurable indoor pollutant is $\mathrm{NO}_{2}$ produced by unvented gas cooking, kerosene and propane space heaters, ETS, and wood heating indoors, and by penetration from outdoors. $\mathrm{NO}_{2}$ has been shown to cause lung damage at high concentrations [25]. $\mathrm{NO}_{2}$ may penetrate the conducting airways also at moderate levels and produce respiratory symptoms and irritative symptoms of the nose and eyes [25].

Few studies on the relationship between indoor $\mathrm{NO}_{2}$ and health in adults or the elderly have been reported (table 2) [25, 26-28]. The Po Delta study [23] showed an association of relatively low levels of indoor $\mathrm{NO}_{2}$ with increased occurrence of acute respiratory symptoms and reduced PEF in adults. Bronchitic and asthmatic symptoms were significantly more prevalent in the presence of high $\mathrm{NO}_{2}$ exposure. High $\mathrm{NO}_{2}$ exposure was associated with greater symptom duration. Increase in $\mathrm{NO}_{2}$ exposure was also associated with an increase in both max amplitude and diurnal variation of PEF, the associations being significant only in subjects with chronic respiratory diseases (i.e. asthma and bronchitis).

A study of British adults [26] showed a significantly reduced forced expiratory volume in one second (FEV1) in subjects who currently used gas for cooking compared to those who

Table 2. - Indoor nitrogen dioxide $\left(\mathrm{NO}_{2}\right)$ levels and lung function and respiratory symptoms/diseases in selected studies of adults

\begin{tabular}{|c|c|c|c|c|}
\hline $\begin{array}{l}\text { First author } \\
\text { [ref no.] }\end{array}$ & $\begin{array}{l}\text { Country } \\
\text { of study }\end{array}$ & Risk factor & Disease/condition & \\
\hline SIMONI [23] & Italy & $\begin{array}{l}\mathrm{NO}_{2} \text { exposure high versus low (in subjects } \\
\text { with chronic bronchitis) } \\
\mathrm{NO}_{2} \text { exposure high versus low (in all subjects) }\end{array}$ & $\begin{array}{l}\text { PEF variation } \\
\text { Max amplitude } \\
\text { Diurnal variation } \\
\text { Respiratory illness }\end{array}$ & $\begin{array}{l}\text { OR }(95 \% \mathrm{CI}) \\
2.03(1.14-3.61) \\
1.84(1.05-3.24) \\
1.50(0.96-2.33)\end{array}$ \\
\hline PILOTTO [27] & Australia & Presence of gas heaters indoors: yes versus no & Asthma & $3.30(1.40-7.64)$ \\
\hline MORAN [26] & Britain & Fuel used for cooking: gas versus electricity & $\begin{array}{l}\text { Lung function } \\
\text { FEV1 } \\
\text { FVC }\end{array}$ & $\begin{array}{l}\text { Variation } \mathrm{mL} \\
-70 \\
-35\end{array}$ \\
\hline NG [28] & Singapore & Frequency of gas cooking: high versus low & FEV1 & -10 \\
\hline NG [28] & Singapore & $\begin{array}{l}\text { Frequency of gas cooking } \\
\text { Low } \\
\text { High }\end{array}$ & Breathlessness & $\begin{array}{l}\text { Prevalence \% } \\
16.9 \\
23.3\end{array}$ \\
\hline
\end{tabular}

OR: odds ratio; CI: confidence interval; PEF: peak expiratory flow; FEV1: forced expiratory volume in one second; FVC: forced vital capacity. 
used electricity. In an Australian study [27] the presence of gas heaters at home was significantly associated with increased prevalence of asthma in males. Gas cooking was also associated with increased risk of respiratory symptoms and impaired lung function in nonsmoking women in Singapore [28].

ETS is a common indoor exposure in many countries and it is a major contributor to indoor RSP concentrations. It constitutes $>4000$ compounds, many of them known carcinogens and irritants [8, 29]. Issues on ETS exposure assessment have been discussed before [30-31]. The research on health effects of ETS has expanded since the 1980's, focusing on children and lung cancer in adults [8]. Table 3 summarises the aetiological studies of ETS and respiratory health in the elderly [32]. It also presents a judgment on causality of the relationships, based on the amount of studies, their validity, evidence of dose-response relationships, and biological plausibility.

There is convincing evidence that ETS causes lung cancer and coronary heart disease, both of which are diseases of the elderly [8, 32-35]. Several cross-sectional studies have shown increased occurrence of chronic respiratory symptoms and deficits in ventilatory lung function in relation to ETS exposure at home and/or at work [8, 13, 28, 32, 36-40]. A limited number of studies have investigated the relationship between ETS exposure and asthma, chronic obstructive pulmonary disease (COPD) and pneumococcal infections in the elderly, but all of them indicate an increased risk among those exposed to ETS [13, 32, 41-44].

More longitudinal studies are needed on ETS and respiratory diseases among the elderly, since even small changes in respiratory function may have a critical impact on the quality of life of the elderly. Moreover, it is important to assess the effects of ETS exposure on elderly people with a pre-existing

Table 3. - Summary of aetiological studies on environmental tobacco smoke and respiratory diseases and conditions in the elderly [32]

\begin{tabular}{|c|c|c|}
\hline $\begin{array}{l}\text { Disease/condition } \\
\text { [ref no. of study] }\end{array}$ & $\begin{array}{l}\text { OR }(95 \% \mathrm{CI}) \text { or } \\
\text { range in } \mathrm{OR}^{\S}\end{array}$ & Causality $^{\#}$ \\
\hline Lung cancer & & $+1+$ \\
\hline Home exposure [33] & $1.23(1.13-1.34)$ & \\
\hline Work exposure [34] & $1.25(1.08-1.41)$ & \\
\hline $\begin{array}{l}\text { Chronic respiratory } \\
\text { symptoms }\end{array}$ & & ++ \\
\hline Wheezing & $1.35-2.69$ & \\
\hline Cough & $2.80-3.79$ & \\
\hline Phlegm & $1.60-3.40$ & \\
\hline Dyspnoea & $1.35-4.50$ & \\
\hline Asthma & $1.45-1.97$ & ++ \\
\hline COPD & $1.68-5.63$ & ++ \\
\hline Respiratory infections [44] & $2.5(1.2-5.1)$ & + \\
\hline \multicolumn{3}{|l|}{ Lung function parameter } \\
\hline $\begin{array}{l}\text { Cross-sectional studies } \\
\text { [39] FEV1 }\end{array}$ & $-2.7 \%(-4.1--1.2 \%)^{\top}$ & + \\
\hline $\begin{array}{l}\text { Longitudinal study [39] } \\
\text { FEV1 }\end{array}$ & No significant affect & 0 \\
\hline
\end{tabular}

§. Odds ratio (OR) and $95 \%$ confidence interval (CI) from metaanalysis (reference given in brackets) or, if a summary estimate is not available, range of OR's from individual studies, lung function parameter data given as effect estimate $(95 \% \mathrm{CI}) ;{ }^{\#}$ : Causality as judged by the authors. Meaning of the symbols is the following. ${ }^{++}$: causal relationship established; ${ }^{++}$: strong evidence of a causal relationship; ${ }^{+}$: some evidence of a causal relationship; 0: no clear evidence of a causal relationship. ": The difference in forced expiratory volume in one second (FEV1) level between the exposed and unexposed, expressed as a percentage of the level in the unexposed group. COPD: chronic obstructive pulmonary disease. disease that may restrict them to indoor environments with possible very high levels of ETS exposure [32]. Surprisingly few studies [32, 44 48] have evaluated the role of ETS in determining the prognosis of an established disease, such as asthma or COPD, although this may be critical for the ability of the elderly to function in everyday life [32].

\section{Methods of indoor surveys}

To investigate the exposure distributions and respiratory effects of $\mathrm{NO}_{2}$, RSP, and ETS, two panel studies were performed in 1991-1994 in subsamples of two randomised stratified samples of Italian general populations, studied previously in cross-sectional surveys $[11,12,49]$.

Subsamples were selected to include subjects fulfilling the following criteria: 1) subjects with current asthma and/or asthmatic symptoms; 2) subjects with bronchial hyper-reactivity (defined as provocative dose causing a $10 \%$ fall in FEV1 (PD10) $<2.4 \mathrm{mg}$ in methacholine challenge); 3) current smokers without asthmatic symptoms or bronchial hyper-reactivity; 4) "healthy" subjects, who were neither active or passive smokers nor had asthmatic symptoms or bronchial hyper-reactivity; 5) some other subjects not included in the previous groups [23, 50]. One study took place in the Po Delta area in Northern Italy ( $n=428,140$ houses investigated) [3] and the other in Pisa in Central Italy ( $n=761,282$ houses investigated) [15].

Information on home characteristics and smoking and other habits of the family were inquired with a modified version of the new EPA standardised environmental inventory questionnaire [3].

Study subjects filled in a daily diary on daily activity pattern (the number of hours spent at home, cooking or doing other activities, the number of hours spent at work or in the school, in other indoor locations, in transit, and outdoors) and on the occurrence of acute respiratory symptoms (allergic symptoms and acute respiratory illnesses and irritative symptoms) during the study weeks. The following were considered acute symptoms: runny nose, sore throat, sputum production from the chest, chest cold, shortness of breath, attack of shortness of breath, wheeze, and red, itchy, watery or burning eyes. Occurrence of chronic symptoms and diseases, such as asthma and bronchitis, were inquired in the previous cross-sectional studies [11, 12]. To assess lung function, each subject performed PEF measurements four times daily using a mini-Wright peak flow meter.

To assess exposure, each house was monitored for 1 week in winter and 1 week in summer to measure RSP (i.e. particles with an aerodynamic diameter $<2.5 \mu \mathrm{m}$, in $\mu \mathrm{g} \cdot \mathrm{m}^{-3}$ ) and $\mathrm{NO}_{2}$ (in parts per billion (ppb)). RSP sampling was performed by active sampling (two $48 \mathrm{~h}$ samples) using a Dorr Oliver-type preselector [3]. The mean of the two 48-h values during the study week was used in the analyses. $\mathrm{NO}_{2}$ sampling was carried out with passive samplers (Palmes tubes) during each week and analysed with spectrophotometric techniques (Saltzman reaction) [3]. Indices of exposure to $\mathrm{NO}_{2}\left(\mathrm{NO}_{2}\right.$-IndEx) and to RSP (RSP-IndEx) were computed as the product of the weekly mean concentration and the daily duration of exposure (i.e. the time spent at home). The indices were considered "low" or "high" based on values below or above the median value.

The Chi-squared test was used to test the differences in occurrence of respiratory symptoms between the exposure groups and nonparametric Mann-Whitney U-test for comparing exposure and time distributions. Multiple linear regression analysis, adjusting for the season, sex, height and weight, was applied to study the relationship between exposures and the mean daily PEF levels. A p-value $<0.05$ was 
Table 4.-Daily activity pattern (in hours) by age group in winter and in summer in the Po Delta and Pisa areas

\begin{tabular}{|c|c|c|c|c|c|c|c|c|c|c|}
\hline \multirow[t]{2}{*}{ Age yrs } & \multirow[t]{2}{*}{ Subjects n } & \multicolumn{3}{|c|}{ At home } & \multicolumn{3}{|c|}{ Total indoors } & \multicolumn{3}{|c|}{ Outdoors } \\
\hline & & Mean (SD) & $\%$ & Median & Mean (SD) & $\%$ & Median & Mean (SD) & $\%$ & Median \\
\hline \multicolumn{11}{|l|}{ Winter } \\
\hline $8-14$ & 99 & $15.7(3.7)$ & 65 & 16 & $21.4(3.2)$ & 89 & 22 & $1.9(2.0)$ & 8 & 1 \\
\hline $15-64$ & 1031 & $15.5(4.8)$ & 65 & 15 & $20.5(4.0)$ & 85 & 22 & $2.1(2.5)$ & 9 & 1 \\
\hline$\geqslant 65$ & 59 & $18.1(4.7)^{* * *}$ & 75 & 15 & $19.8(4.8)$ & 83 & 20 & $2.9(2.7)$ & 12 & 2 \\
\hline \multicolumn{11}{|l|}{ Summer } \\
\hline 8-14 & 94 & $14.8(4.0)$ & 62 & 15 & $17.9(3.5)$ & 75 & 18 & $5.4(3.3)$ & 23 & 5 \\
\hline $15-64$ & 969 & $14.2(5.0)$ & 59 & 14 & $18.5(5.0)$ & 77 & 20 & $3.7(3.5)$ & 15 & 3 \\
\hline$\geqslant 65$ & 61 & $15.9(6.1)^{* * *}$ & 66 & 17 & $17.3(6.2)$ & 72 & 19 & $4.0(3.4)$ & 17 & 3 \\
\hline
\end{tabular}

\#: home + work/school + other indoor places; $* * *: p<0.001$ by Mann-Whitney U-test between $\geqslant 65$ age group and the other age groups both in winter and summer.

considered as statistically significant. Analyses on the effects of indoor pollutants on respiratory symptoms in the elderly were performed on subjects $\geqslant 65 \mathrm{yrs}(\mathrm{n}=59$ and 61 in winter and summer, respectively).

\section{Results}

Subjects living in the Po Delta and Pisa areas spent most of their day indoors. Older subjects spent a significantly $(p<0.001)$ higher number of hours at home daily compared to subjects of the other age groups (table 4). Home concentrations of $\mathrm{NO}_{2}$ and RSP were significantly higher in winter than in summer (21 versus $15 \mathrm{ppb}$ for $\mathrm{NO}_{2} ; 77$ versus $49 \mathrm{mg} \cdot \mathrm{m}^{-3}$ for RSP). The highest values of $\mathrm{NO}_{2}$ were found in the kitchens (33 and $20 \mathrm{ppb}$ in winter and summer, respectively).

Analyses in older subjects ( $\geqslant 65$ yrs) of the Po Delta $[3,23]$ and Pisa [15] showed a trend of higher occurrence of acute respiratory symptoms in relation to ETS exposure both in winter (31\% in ETS exposed versus $29 \%$ in unexposed) and in summer $(33 \%$ versus $16 \%, \mathrm{p}<0.001)$ (fig. 1$)$. The occurrence of acute respiratory symptoms was consistently higher in relation to high RSP exposure compared to low exposure (33 versus $27 \%$ in winter, 27 versus $21 \%$ in summer), although the differences were not statistically significant (fig. 1). Presence of ETS at home was associated with a decrease in the mean daily PEF (effect estimate: $-19.2 \mathrm{~L} \cdot \mathrm{min}^{-1}, \mathrm{p}<0.01$ ). In these analyses, $\mathrm{NO}_{2}$ exposure did not affect the occurrence of acute respiratory symptoms or lung function.

\section{Discussion}

People have been shown to spend $\sim 80-90 \%$ of their day indoors, and this percentage increases in the elderly. The Po Delta and Pisa studies confirmed that people $\geqslant 65$ yrs spend a significantly larger number of hours at home compared to people of the younger age groups. This finding underlines the importance of indoor air quality studies in the elderly, who may be especially susceptible to effects of low concentrations of pollutants because of underlying chronic diseases. It also confirms that, in epidemiological studies, it is important to assess exposures from outdoor and indoor sources separately, as suggested by the U.S. Environmental Protection Agency [29].

Health effects of indoor air pollutants have been addressed in studies of infants and children [1, 4-10], but only a few studies have investigated such effects in adults and in older people [14, 23, 24, 26-28]. Previous results of the Po Delta study [23] showed an association of relatively low levels of indoor pollutants (e.g. RSP $77 \mu \mathrm{g} \cdot \mathrm{m}^{-3}$ in winter and $49 \mu \mathrm{g} \cdot \mathrm{m}^{-3}$ in summer, $\mathrm{NO}_{2} 21 \mathrm{ppb}$ in winter and $15 \mathrm{ppb}$ in summer) with acute respiratory symptoms and reduced PEF in adults. The results in older subjects living in the Po Delta and Pisa areas showed consistently higher occurrence of acute respiratory symptoms in relation to high RSP exposure as compared to low exposure. In addition, the high RSP-index was significantly associated with a decrease in the mean daily PEF. This finding is consistent with the negative association between
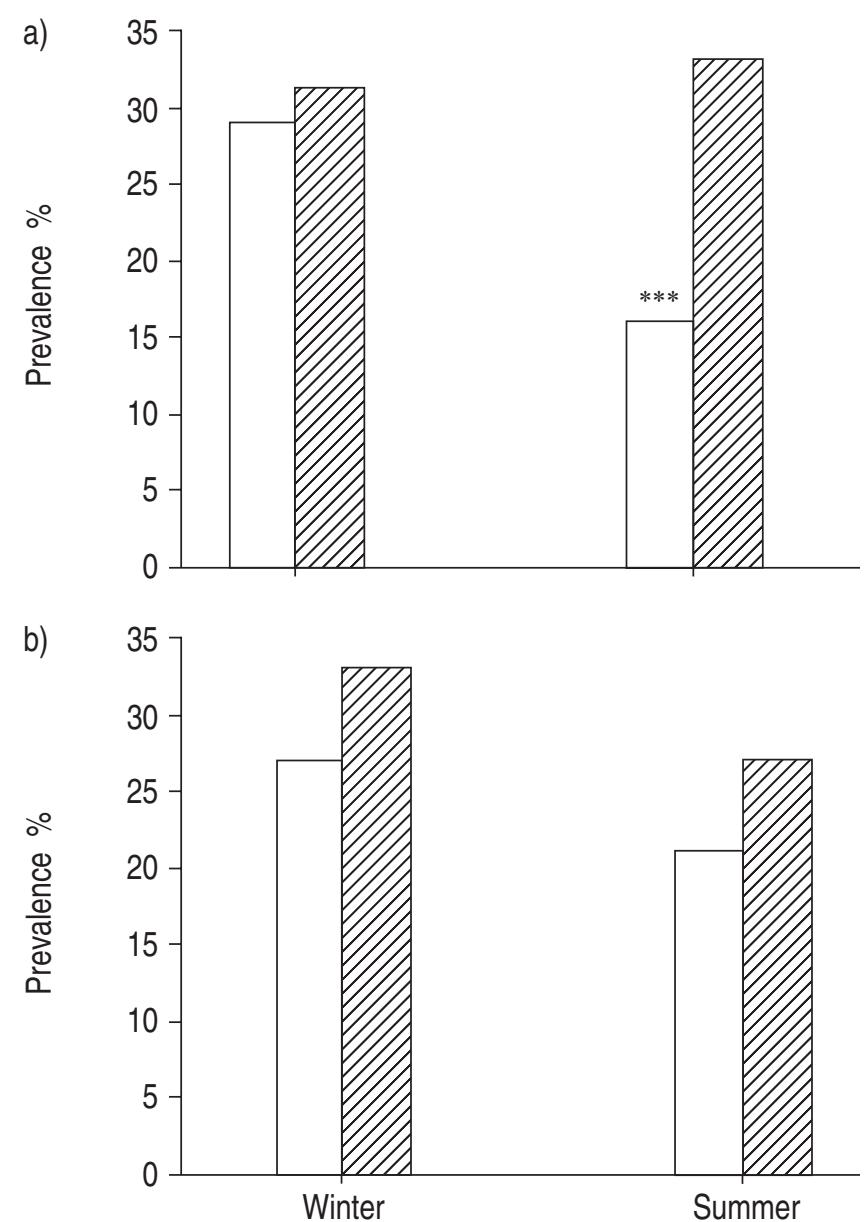

Fig. 1.-Occurrence of acute respiratory symptoms in relation to a) environmental tobacco smoke exposure at home $(\square$ : not present; $\mathbb{Z}$ : present) and to b) the respirable suspended particles-index ( $\square$ : low; $\mathbb{Z}$ : high). Data from the Po Delta and Pisa studies $[3,23,15]$. ***: $\mathrm{p}<0.001$ by Chi-squared test. 
RSP and PEF found in earlier studies of indoor [14] and outdoor [51] pollutants.

The present authors' finding of a trend of increased acute respiratory symptoms in relation to ETS exposure is in accordance with an earlier study of acute symptoms in nurses [37] and with several studies on ETS and chronic respiratory symptoms in adults [8, 13, 28, 32, 36, 38]. ETS exposure was also significantly associated with a decrease in the mean daily PEF, which points out that there are small effects of ETS on lung function impairment (table 3) [8, 32, 39].

There is a clear need for more studies on indoor pollution and health in adults, and especially in the elderly. Further development of exposure assessment methodology is a major challenge for the future. Future studies should address both short-term and long-term health effects related to indoor air pollutants. Identification of subgroups among the elderly who are susceptible to the adverse effects of air pollutants would also be an important step to support preventive measures. Few studies have evaluated the role of indoor pollutants in determining the prognosis of pre-existing diseases. Such studies may become an important new area for research, especially among the elderly, who often have chronic diseases restricting them to indoor environments with possible high levels of exposure to indoor pollutants.

In conclusion, the current results in people of $\geqslant 65 \mathrm{yrs}$ confirm that older people spend more time at home than younger subjects, emphasising the importance of good indoor air quality for the maintenance of the health of the elderly. In older people, exposure to RSP and ETS is related to increased occurrence of acute respiratory symptoms and reduced lung function.

There is a clear need for more studies on indoor pollutants and health in the elderly, with focus on improved exposure assessment, various types of short-term and long-term health outcomes, and identification of characteristics associated with susceptibility to the adverse effects.

The potential role of indoor pollutants as a prognostic factor determining the development of a pre-existing disease may be an important new area for research.

\section{References}

1. Bruce N, Perez-Padilla R, Albalak R. Indoor air pollution in developing countries: a major environmental and public health challenge. Bull World Health Organ 2000; 78: 10781092 .

2. Books BO, Utter GM, DeBroy JA, Schimke RD. Indoor air pollution: an edifice complex. Clin Toxicol 1991; 29: 315-374.

3. Simoni M, Biavati P, Carrozzi L, et al. The Po river delta (North Italy) indoor epidemiological study: home characteristics, indoor pollutants, and subjects' daily activity pattern. Indoor Air 1998; 8: 70-79.

4. Neas LM, Dockery DW, Ware JH, Spengler JD, Speizer FE, Ferris BG. Association of indoor nitrogen dioxide with respiratory symptoms and pulmonary function in children. Am J Epidemiol 1991; 134: 204-219.

5. Neas LM, Dockery DW, Ware JH, Spengler JD, Ferris BG, Speizer FE. Concentration of indoor particulate matter as a determinant of respiratory health in children. Am J Epidemiol 1994; 139: 1088-1099.

6. Nafstad P, Jaakkola JJK, Hagen JA, Botten G, Kongerud J. Breastfeeding, maternal smoking and lower respiratory tract infections. Eur Respir J 1996; 9: 2623-2629.

7. Nafstad P, Kongerud J, Botten G, Hagen JA, Jaakkola JJK. The role of passive smoking in the development of bronchial obstruction during the first 2 years of life. Epidemiology 1997; 8: 293-297.

8. Jaakkola MS. Environmental tobacco smoke and respiratory diseases. Eur Respir Mon 2000; 5: 15, 322-383.
9. Jaakkola JJK, Nafstad P, Magnus P. Environmental tobacco smoke, parental atopy, and childhood asthma. Environ Health Perspect 2001; 109: 579-582.

10. Jaakkola JJK, Jaakkola MS. Effects of environmental tobacco smoke on respiratory health in children. Scand $J$ Work Environ Health 2002; 28: Suppl. 2, 71-83.

11. Viegi G, Carrozzi L, Paoletti P, et al. Effects of some indoor environmental factors on respiratory symptoms and lung function in a sample of young non smokers in North Italy. Aerobiologia 1991; 7: 152-159.

12. Viegi G, Carrozzi L, Paoletti P, et al. Effects of the home environment on respiratory symptoms of a general population sample in Middle Italy. Arch Environ Health 1992; 47: 64-70.

13. Leuenberger P, Schwartz J, Ackermann Liebrich U, et al. Passive smoking exposure in adults and chronic respiratory symptoms (SAPALDIA Study). Am J Respir Crit Care Med 1994; 150: 1222-1228.

14. $\mathrm{Xu} \mathrm{X}$, Wang L. Association of indoor and outdoor particulate level with chronic respiratory illness. Am Rev Respir Dis 1993; 148: 1516-1522.

15. Baldacci S, Carrozzi L, Viegi G, Giuntini C. Assessment of respiratory effect of air pollution: study design on general population samples. JEPTO 1997; 16: 77-83.

16. Samet JM, Utell MJ. The environment and the lung. JAMA 1991; 266: 670-675.

17. Sunyer J, Schwartz J, Tobias A, Macfarlane D, Garcia J, Anto JM. Patients with chronic obstructive pulmonary disease are at increased risk of death associated with urban particle air pollution: a case-crossover analysis. $\mathrm{Am} J$ Epidemiol 2000; 151: 50-56.

18. Tellez Rojo MM, Romieu I, Ruiz-Velasco S, Lezana MA, Hernandez-Avila MM. Daily respiratory mortality and PM10 pollution in Mexico City: importance of considering place of death. Eur Respir J 2000; 16: 391-396.

19. Janssen NA, de Hartog JJ, Brunekreef B, Lanki T, Timonen KL, Pekkanen J. Personal exposure to fine particulate matter in elderly subjects: relation between personal, indoor, outdoor concentration. J Air Waste Manag Assoc 2000; 50: 11331143 .

20. Ramachandran G, Adgate JL, Hill N, Sexton K, Pratt GC, Bock D. Comparison of short-term variation (15-minute averages) in outdoor and indoor PM2.5 concentrations. J Air Waste Manag Assoc 2000; 50: 1157-1166.

21. Sarnat JA, Koutrakis P, Suh HH. Assessing the relationship between personal particulate and gaseous exposures of senior citizen living in Baltimore, MD. J Air Waste Manag Assoc 2000; 50: 1184-1198

22. Rojas-Bracho L, Suh HH, Koutrakis P. Relationship among personal, indoor, and outdoor fine and coarse particle concentrations for individuals with COPD. J Expo Anal Environ Epidemiol 2000; 10: 294-306.

23. Simoni M, Carrozzi L, Baldacci S, et al. The Po river delta (North Italy) epidemiological study: effect of pollutant exposure on acute respiratory symptoms and respiratory function in adults. Arch Environ Health 2002; 57: 130-136.

24. Venners SA, Wang B, Ni J, et al. Indoor air pollution and respiratory health in urban and rural China. Int $J$ Occup Environ Health 2001; 7: 173-181.

25. Alberts WM. Indoor air pollution: $\mathrm{NO}, \mathrm{NO}_{2}, \mathrm{CO}, \mathrm{CO}_{2} . \mathrm{J}$ All Clin Immunol 1994; 94: 289-295.

26. Moran SE, Strachan DP, Johnston ID, Anderson HR. Effects of exposure to gas cooking in childhood and adulthood on respiratory symptoms, allergic sensitization and lung function in young British adults. Clin Exp Allergy 1999; 29: 1033-1041.

27. Pilotto LS, Smith BJ, Nitschke M, Ruffin RE, Mitchell R. Industry, air quality, cigarette smoking and rates of respiratory illness in Port Adelaide. Aust $N Z J$ Public Health 1999; 23: 657-660.

28. Ng TP, Hui KP, Tan WC. Respiratory symptoms and lung function effects of domestic exposure to tobacco smoke and 
cooking by gas in non-smoking women in Singapore $J$ Epidemiol Community Health 1993; 47: 454458.

29. U.S. Environmental Protection Agency. Respiratory health effects of passive smoking: lung cancer and other disorders. EPA/600/6-90/006F. Washington DC, U.S. Environmental Protection Agency, Office of Health and Environmental Assessment, Office of Research and Development, 1992.

30. Jaakkola MS, Jaakkola JJK. Assessment of exposure to environmental tobacco smoke. Eur Respir J 1997; 10: 2384 2397.

31. Jaakkola MS, Samet JM. Occupational exposure to environmental tobacco smoke and health risk assessment. Environ Health Perspect 1999; 107: 829-835.

32. Jaakkola MS. Environmental tobacco smoke and health in the elderly. Eur Respir J 2002; 19: 172-181.

33. Hackshaw AK, Law MR, Wald NJ. The accumulated evidence on lung cancer and environmental tobacco smoke. Br Med J 1997; 315: 980-988.

34. Brown KG. Lung cancer and environmental tobacco smoke: Occupational risk to nonsmokers. Environ Health Perspect 1999; 107: 885-890.

35. Jaakkola MS, Samet JM. Summary: workshop on health risks attributable to ETS exposure in the workplace. Environ Health Perspect 1999; 107: 823-827.

36. Eisner MD, Smith AK, Blanc PD. Bartenders' respiratory health after establishment of smoke-free bars and taverns. JAMA 1998; 280: 1909-1914.

37. Schwartz J, Zeger S. Passive smoking, air pollution, and acute respiratory symptoms in a diary study of student nurses. Am Rev Respir Dis 1990; 141: 62-67.

38. Jaakkola MS, Jaakkola JJK, Becklake MR, Ernst P. Effect of passive smoking on the development of respiratory symptoms in young adults: an 8-year longitudinal study. $J$ Clin Epidemiol 1996; 49: 581-586.

39. Carey IM, Cook DG, Strachan DP. The effects of environmental tobacco smoke exposure on lung function in a longitudinal study of British adults. Epidemiology 1999; 10: 319-326.

40. Jaakkola MS, Jaakkola JJK, Becklake MR, Ernst P. Passive smoking and evolution of lung function in young adults: an 8-year longitudinal study. J Clin Epidemiol 1995; 48: 317-327.
41. Greer JR, Abbey DE, Burchette RJ. Asthma related to occupational and ambient air pollutants in nonsmokers. J Occup Med 1993; 35: 909-915.

42. Flodin U, Jönsson P, Ziegler J, Axelson O. An epidemiologic study of bronchial asthma and smoking. Epidemiology 1995; 6: $503-505$.

43. Robbins AS, Abbey DE, Lebowitz MD. Passive smoking and chronic respiratory symptoms in non-smoking adults. Int J Epidemiol 1993; 22: 809-817.

44. Jaakkola MS, Piipari R, Jaakkola N, Jaakkola JJK. Environmental tobacco smoke and development of adultonset asthma: a population-based incident case-control study. Am J Public Health 2003 (in press).

45. Nuorti JP, Butler JC, Farley MM, et al. Cigarette smoking and invasive pneumococcal disease. $N$ Engl J Med 2000; 342: 681-689.

46. Sippel JM, Pedula KL, Vollmer WM, Buist AS, Osborne ML. Associations of smoking with hospital-based care and quality of life in patients with obstructive airway disease. Chest 1999; 115: 691-696.

47. Blanc PD, Ellbjär S, Janson C, et al. Asthma-related work disability in Sweden. The impact of workplace exposures. Am J Respir Crit Care Med 1999; 160: 2028-2033.

48. Mannino DM, Siegel M, Rose D, Nkuchia J, Etzel R Environmental tobacco smoke exposure in the home and worksite and health effects in adults: results from the 1991 National Health Interview Survey. Tobacco Control 1997; 6: 296-305.

49. Carrozzi L, Giuliano G, Viegi G, et al. The Po river delta epidemiological study of obstructive lung disease: sampling methods, environmental and population characteristics. Eur J Epidemiol 1990; 6: 191-200.

50. Sapigni T, Simoni M, Biavati P, et al. The Po river Delta (north Italy) indoor epidemiological study: organisation and study methods. Indoor Air: Proceedings of the $6^{\text {th }}$ International Conference on Indoor Air Quality and Climate, Helsinki 1993; 1: 815-820.

51. Leuenberger P, Künzli N, Ackermann Liebrich U, et al. Swiss study on air pollution and lung diseases in adults (SAPALDIA). Schwiz Med Wochenschr 1998; 128: 150161. 